Original Article

\title{
Effects of Cast Immobilisation on Skin Barrier Function
}

Chin Yee Woo, ${ }^{1} M B B S$, MRCSEd, Mark JA Koh, ${ }^{2} M D$, Winnie KY Fung, ${ }^{3} P h D$, Cheri SH $\underline{\text { Chan }},{ }^{3}{ }_{B S c}(H o n s)$, Chong Bing Chua, ${ }^{1} M D$, Guan Tzu Tay, ${ }^{1}$ MMed (Ortho), FRCSEd (Ortho), Sanchalika Acharyya, ${ }^{4}{ }_{P h D}$, Gloria FH Chew, ${ }^{3} D B T$, Nicole KL Lee, ${ }^{3} P h D$,

Kevin BL $\underline{\text { Lim }},{ }^{1}$ FRCS (Eng), FRCSEd (Ortho), FAMS (Orthopaedic Surgery)

\begin{abstract}
Introduction: Cast immobilisation remains the mainstay of treatment for various fractures in paediatric patients, yet patients commonly complain of skin irritation and discomfort. This study aimed to perform a qualitative and quantitative evaluation of the effects of cast immobilisation on the skin of children and adolescents. Materials and Methods: Patients aged 6-17 years of age with a fracture treated in a fiberglass short-arm or short-leg cast were recruited. Transepidermal water loss (TEWL), stratum corneum (SC) hydration, hair density and presence of any skin signs were assessed before and after cast. Patients were required to complete a weekly questionnaire to rate itch, malodour, warmth, and dampness of the skin under the cast. Results: A total of 60 subjects completed the study. Thirty-six patients received a short-arm cast; 24 received a short-leg cast. Upon cast removal, TEWL was significantly increased on the volar surface of the arms and legs $(P<\mathbf{0 . 0 5})$, and the dorsal surface of the arm $(P<0.05)$. Likewise, SC hydration was significantly increased at most sites $(P<0.05)$, except the volar surface of the leg $(P=\mathbf{0 . 5 1 3})$. There was no change in hair density. Throughout the duration of casting, there was an increase in itch and malodour scores. Conclusions: Moderate but significant changes in TEWL, SC hydration and subjective symptoms were observed during the duration of cast immobilisation, demonstrating that cast immobilisation for up to 4 weeks exerts moderate adverse impact on patients' skin. Further studies to explore the use of better materials for cast immobilisation to improve skin barrier function and overall patient satisfaction are warranted.
\end{abstract}

Ann Acad Med Singapore 2020;49:354-59

Key words: Cast immobilisation, Transepidermal water loss, Stratum corneum hydration

\section{INTRODUCTION}

Fractures account for up to $25 \%$ of all paediatric injuries. ${ }^{1}$ Cast immobilisation remains the mainstay of treatment in many paediatric acute fractures, with the period of casting ranging from 2 to 8 weeks depending on the type of injury. Skin irritation, itch, discomfort and malodour are commonly encountered during and after casting, especially in hot and humid environments. ${ }^{2,3}$ Complications from casting, such as hypertrichosis, xerosis, skin atrophy and ulcerations have been reported in adults and children. ${ }^{4-8}$ However, none of the existing studies objectively evaluates the effect of cast immobilisation on the skin. Our study aimed to evaluate the effects of cast immobilisation on the skin of children and adolescents both qualitatively and quantitatively by measuring transepidermal water loss (TEWL), stratum corneum (SC) hydration, hair density, as well as clinical assessment of the skin and patients' self-assessment of discomfort associated with cast immobilisation.

\footnotetext{
'Department of Orthopaedic Surgery, KK Women's and Children's Hospital, Singapore

${ }^{2}$ Dermatology Service, KK Women's and Children's Hospital, Singapore

${ }^{3}$ Division of Surgery, KK Women's and Children's Hospital, Singapore

${ }^{4}$ Centre for Qualitative Medicine, Duke-NUS Medical School

Address for Correspondence: A/Prof Mark Jean Aan Koh, Dermatology Service, KK Women's and Children's Hospital, 100 Bukit Timah Road, Singapore 229899 Email: mark.koh.j.a@singhealth.com.sg
} 


\section{Materials and Methods}

\section{Study Design}

We performed a prospective qualitative and quantitative evaluation of the effects of cast immobilisation on the skin. The study was approved by the SingHealth Centralised Institutional Review Board (CIRB) and supported by a grant from the KK Women's and Children's Hospital (KKH) Health Endowment Fund. Patients were recruited from an outpatient Orthopaedic Surgery clinic at KKH, a tertiary paediatric hospital in Singapore, between January and June 2015. Informed consent was obtained from parents or legal guardians. Inclusion criteria were children and adolescents between 6 and 17 years of age with a fracture amenable to treatment in either a short-arm or short-leg cast, using standard materials of fiberglass cast over a layer of cotton stockinet liner with cotton undercast padding. Exclusion criteria were fractures that required surgical fixation, treatment in a long-limb or other cast configurations (e.g. hip spica), or the use of a non-standard cast material (e.g. waterproof Hybrid Mesh cast). Paediatric patients with a fracture would usually be attended to by the hospital's Children's Emergency Department or primary care clinic. Fractures that do not require surgical fixation will be treated by the emergency department or primary care clinic with a backslab cast in the acute period. A new fiberglass cast would then be applied at our Orthopaedic Surgery outpatient clinic 3-7 days later. At this clinic visit, patients were invited to enrol in this study.
One study investigator would take three independent measurements of TEWL, SC hydration, hair density, and observe the condition of the skin on both volar and dorsal surfaces of the injured arm or leg. To ensure that the same skin area was measured before cast application and after cast removal, a measuring guide consisting of three sets of $3 \times 3 \mathrm{~cm}$ grids were overlaid approximately $5 \mathrm{~cm}$ below the elbow crease and kneecap. All measurements were taken within the designated grids.

TEWL was measured using the Delfin Vapometer ${ }^{\mathrm{TM}}$ and registered in $\mathrm{g} / \mathrm{h} / \mathrm{m}^{2}$; SC hydration was measured using the Delfin Moisture Meter $\mathrm{SC}^{\mathrm{TM}}$ and registered in units. At the follow-up clinic review, after the cast was removed, repeat assessments of the same parameters were performed. Similarly, photographs of the injured limbs within the designated boxes were taken using a digital SLR camera with a macro lens and ring light flash before cast application and after cast removal. Total number of visible hair follicles per unit area of hair in all photographs were counted independently. A localised skin examination was performed by the same investigator, noting any rash, abnormal pigmentation, ulceration or abrasion before application and after removal of the cast. These findings were documented as present or absent. If present, further description of the skin findings and severity were documented. Lastly, patients were required to complete a weekly questionnaire (Table 1) to rate levels of itch, malodour, warmth, and dampness of the skin under the cast during the duration of casting, with 1 being the worst rating and 5 being the best rating for each category.

Table 1. Patient Experience Questionnaire

1. Circle the option that best applies during the casting period:

\begin{tabular}{|c|c|c|c|c|c|}
\hline \multicolumn{2}{|r|}{ Itch } & \multicolumn{2}{|r|}{ Odour } & \multicolumn{2}{|r|}{ Heat and dampness } \\
\hline 5 & Not itchy at all & 5 & Not smelly at all & 5 & I don't feel it more than usual \\
\hline 4 & $\begin{array}{l}\text { It rarely itches } \\
\text { (1 time a week) }\end{array}$ & 4 & It rarely smells & 4 & I only feel it on a warmer day \\
\hline 3 & $\begin{array}{l}\text { It sometimes itches } \\
\text { (2-3 times a week) }\end{array}$ & 3 & $\begin{array}{l}\text { It sometimes smells, usually after a long day } \\
\text { or on a warmer day }\end{array}$ & 3 & $\begin{array}{l}\text { I feel it sometimes but I can relieve it by } \\
\text { staying in an air-conditioned room }\end{array}$ \\
\hline 2 & It itches daily but tolerable & 2 & It smells daily but only when I sniff closely & 2 & I feel it daily but tolerable \\
\hline 1 & $\begin{array}{l}\text { Very itchy and I want my cast } \\
\text { removed }\end{array}$ & 1 & Very smelly and noticeable by others & 1 & $\begin{array}{l}\text { Very warm and damp and I want my cast } \\
\text { removed }\end{array}$ \\
\hline & $\begin{array}{l}\text { Did you do anything to reliev } \\
\text { othing } \\
\text { low cold air from a hairdryer } \\
\text { pply talcum powder into the cas } \\
\text { oray perfume or air freshener ov } \\
\text { ay in air-conditioned room }\end{array}$ & & e discomfort? & & \\
\hline
\end{tabular}




\section{Statistical Methods}

Statistical analyses were performed using the SPSS software version 19.0. Paired samples t-test was used to compare TEWL, SC hydration, and hair density before cast application and after cast removal. A $P$-value of less than 0.05 was considered significant.

\section{Results}

\section{Demographics}

A total of 67 patients were recruited into the study. Of these, 7 patients did not complete the study or were lost to follow-up. Sixty patients completed the study and were included in final data analysis. Four patients had incomplete questionnaire responses and this data was excluded from analysis of the quantitative questionnaire. Of the 60 patients, there were 39 boys $(65 \%)$ and 21 girls $(35 \%)$, with a mean age of 11.8 years (range $=6-17$ years). Thirtythree patients sustained injuries to their right side, while 27 had injuries to their left. A total of 36 short-arm and 24 short-leg casts were applied, with distribution of type of injury shown in Table 2. Their cast duration ranged from 7 to 29 days (median $=21$ days) (Table 2$)$.

\section{Objective Assessments}

As shown in Table 3, upon cast removal, TEWL increased significantly from baseline by $4.20 \mathrm{~g} / \mathrm{h} /$ $\mathrm{m}^{2}(95 \%$ CI: $2.60-5.79 ; P<0.001)$ and $1.26 \mathrm{~g} / \mathrm{h} / \mathrm{m}^{2}$ (95\% CI: $0.15-2.38 ; P=0.028)$ on the volar surface of arm and leg, respectively. However, this change was relatively more modest on the dorsal surface, with TEWL on the arm increased by $1.03 \mathrm{~g} / \mathrm{h} / \mathrm{m}^{2}$ (95\% CI: $0.12-1.93 ; P=0.028)$ and $0.55 \mathrm{~g} / \mathrm{h} / \mathrm{m}^{2}$ on the leg (95\% CI: $-0.37-1.48 ; P=0.226)$. SC hydration increased by 16.87 units $(95 \%$ CI: $9.51-24.23$; $P<0.001)$ and $1.51(95 \%$ CI: $-3.18-6.19 ; P=0.513)$ on the volar surface of arm and leg, respectively. On the dorsal surface, SC hydration was significantly increased by 5.45 units (95\% CI: 1.56 - 9.34; $P=0.007)$ on the arm and 6.64 units $(95 \%$ CI: $1.52-$ $11.75 ; P=0.013)$ on the leg. There was no significant difference in hair density before cast application and after cast removal on the arm $(14.63 \pm 6.04$ versus $15.39 \pm 5.50 ; P=0.302)$ or leg $(12.09 \pm 6.32$ versus $12.54 \pm 5.68 ; P=0.364)$. Overall, there was no dyspigmentation or ulcerations detected after cast removal. However, one patient developed abrasions secondary to a pen cap being lodged between the
Table 2. Patient Demographics and Characteristics

\begin{tabular}{|c|c|}
\hline & $N=60$ \\
\hline Age, Mean \pm SD & $11.8 \pm 2.5$ years \\
\hline \multicolumn{2}{|l|}{ Race, n (\%) } \\
\hline Chinese & $30(50)$ \\
\hline Malay & $18(30)$ \\
\hline Indian & $11(18)$ \\
\hline Others & $1(2)$ \\
\hline \multicolumn{2}{|l|}{ Gender, n (\%) } \\
\hline Male & $39(65)$ \\
\hline Female & $21(35)$ \\
\hline \multicolumn{2}{|l|}{ Side of casted limb, n (\%) } \\
\hline Right & $33(55)$ \\
\hline Left & $27(45)$ \\
\hline \multicolumn{2}{|l|}{ Fracture diagnosis, n (\%) } \\
\hline Distal radius buckle fracture & $19(31.7)$ \\
\hline Distal radius greenstick fracture & $6(10)$ \\
\hline Distal radius $\mathrm{SH} 1$ fracture & $6(10)$ \\
\hline Distal radius $\mathrm{SH} 2$ fracture & $3(5)$ \\
\hline Wrist contusion & $2(3.3)$ \\
\hline Distal fibula SH1 fracture & $15(25)$ \\
\hline Distal fibula $\mathrm{SH} 2$ fracture & $1(1.7)$ \\
\hline Ankle sprain & $4(6.7)$ \\
\hline Metatarsal fracture & $3(5)$ \\
\hline Lisfranc fracture & $1(1.7)$ \\
\hline \multicolumn{2}{|l|}{ Fraction location, n (\%) } \\
\hline Upper limb & $36(62)$ \\
\hline Lower limb & $24(38)$ \\
\hline \multicolumn{2}{|l|}{ Type of cast, n (\%) } \\
\hline Below elbow & $36(62)$ \\
\hline Below knee & $24(38)$ \\
\hline \multicolumn{2}{|l|}{ Cast duration, n (\%) } \\
\hline $0-7$ days & $0(0)$ \\
\hline $7.1-14$ days & $17(28.3)$ \\
\hline $14.1-21$ days & $34(56.7)$ \\
\hline $21.1-29$ days & $9(15)$ \\
\hline
\end{tabular}

$\mathrm{SD}=$ Standard deviation; $\mathrm{SH}=$ Salter-Harris 
Table 3. Transepidermal Water Loss (TEWL), SC hydration, and Hair Density before Cast Application and After Cast Removal

\begin{tabular}{|c|c|c|c|c|}
\hline Variable & Before Cast (mean \pm SD) & After Cast (mean \pm SD) & $\begin{array}{c}\text { Differences of means } \\
(95 \% \mathrm{CI})\end{array}$ & $P$ value \\
\hline \multicolumn{5}{|l|}{ Upper Limb $(n=36)$} \\
\hline \multicolumn{5}{|l|}{ TEWL, g/h/m² } \\
\hline Volar & $7.67 \pm 2.39$ & $11.86 \pm 4.85$ & $\begin{array}{c}4.20 \\
(2.60,5.79)\end{array}$ & $<0.001$ \\
\hline Dorsal & $6.68 \pm 2.33$ & $7.70 \pm 2.63$ & $\begin{array}{c}1.03 \\
(0.12,1.93)\end{array}$ & 0.028 \\
\hline \multicolumn{5}{|l|}{ SC hydration, units } \\
\hline Volar & $22.14 \pm 8.14$ & $39.01 \pm 23.04$ & $\begin{array}{c}16.87 \\
(9.51,24.23)\end{array}$ & $<0.001$ \\
\hline Dorsal & $19.72 \pm 6.40$ & $25.17 \pm 12.67$ & $\begin{array}{c}5.45 \\
(1.56,9.34)\end{array}$ & 0.007 \\
\hline Hair Density (hairs/cm²) & $14.63 \pm 6.04$ & $15.39 \pm 5.50$ & $\begin{array}{c}0.76 \\
(-0.72,2.25)\end{array}$ & 0.302 \\
\hline \multicolumn{5}{|l|}{$\underline{\text { Lower Limb }(n=24)}$} \\
\hline \multicolumn{5}{|l|}{ TEWL, g/h/m $\mathrm{m}^{2}$} \\
\hline Volar & $6.76 \pm 1.60$ & $8.03 \pm 2.25$ & $\begin{array}{c}1.26 \\
(0.15,2.38)\end{array}$ & 0.028 \\
\hline Dorsal & $6.73 \pm 1.58$ & $7.28 \pm 2.31$ & $\begin{array}{c}0.55 \\
(-0.37,1.48)\end{array}$ & 0.226 \\
\hline \multicolumn{5}{|l|}{ SC hydration, units } \\
\hline Volar & $20.76 \pm 10.18$ & $22.26 \pm 10.89$ & $\begin{array}{c}1.51 \\
(-3.18,6.19)\end{array}$ & 0.513 \\
\hline Hair Density (hairs/ $\mathrm{cm}^{2}$ ) & $12.09 \pm 6.32$ & $12.54 \pm 5.68$ & $\begin{array}{c}0.45 \\
(-0.55,1.44)\end{array}$ & 0.364 \\
\hline
\end{tabular}

$\mathrm{SD}=$ Standard deviation; $\mathrm{TEWL}=$ Transepidermal water loss $; \mathrm{SC}=$ Stratum corneum

cast and skin (Fig. 1), and another patient developed erythema with some follicular accentuation deemed secondary to skin irritation (Fig. 2A and 2B).

\section{Subjective Assessments}

There was an increase in itch and malodour over the duration of casting, worsening with increasing duration. However, the majority of patients did not feel their skin under the cast was overly warm or moist.

\section{Discussion}

This study measured the skin barrier function and hair density of paediatric patients aged between 6 and 17 years, following immobilisation in a short-arm or short-leg cast. We demonstrated that cast immobilisation increased TEWL and SC hydration on dorsal and volar surfaces of the forearm and lower leg, in varying degrees. In addition, there was an increase in itch and malodour perceived by patients over the duration of casting, but most of them did not report that their skin under the cast was overly warm or moist.

There has been only a handful of studies investigating the effects of cast immobilisation on the skin, with most studies reporting only subjective evaluation of cutaneous symptoms and signs. In a retrospective review of 297 children, DiFazio et al reported skin complications in $28 \%$ of patients who underwent cast immobilisation. ${ }^{2}$ A subsequent prospective study reported a skin complication rate of 13.6 per 1000 casts applied in patients under 18 years of age, 


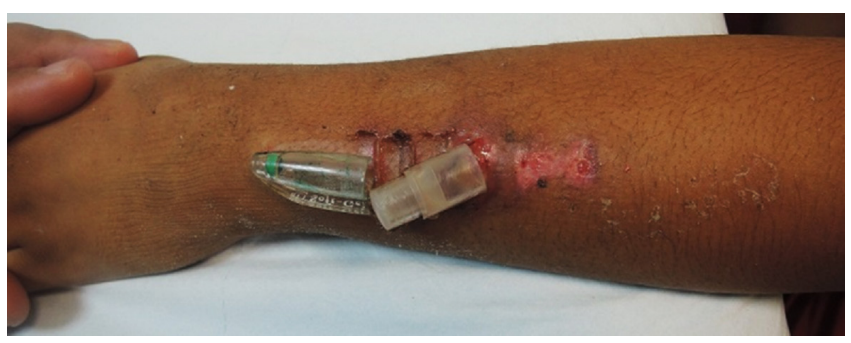

Fig. 1. A patient developed abrasion secondary to a pen cap being lodged between the cast and skin.

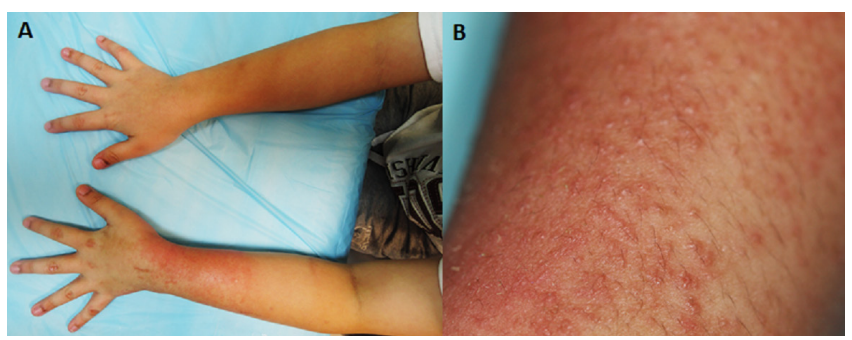

Fig. 2. A patient developed erythema with follicular accentuation.

including erythema, excoriation, wound dehiscence, maceration, and pressure ulcers. ${ }^{3}$ In a prospective study by DiPaola et al, 3\% of paediatric patients had to undergo unplanned cast changes due to skin irritation, while $3 \%$ of patients developed superficial infections requiring treatment with systemic antibiotics. ${ }^{4}$ To the best of our knowledge, our study is the first to objectively examine epidermal barrier function after fiberglass cast immobilisation in a paediatric population.

TEWL is the loss of water across the stratum corneum, the outermost layer of the skin, which functions as the major barrier to diffusion. When the skin barrier is compromised by physical or chemical agents, TEWL would increase. ${ }^{10}$ Our study showed that casting increased TEWL on both volar and dorsal sides of the limbs, albeit to a much lesser extent on the dorsal surface. This may be due to differences in skin structure between the two areas, including differences in thickness of the cornified layer, vascularity, and number and size of sweat glands. ${ }^{11}$ Increased TEWL is known to be associated with skin barrier disruption ${ }^{12}$ and if prolonged and severe, can lead to the development of dermatitis, especially in more susceptible patients.

Our results showed that casting increased the moisture content of stratum corneum on both dorsal and volar surfaces of the casted limbs, except the volar leg. We postulate that due to the low permeability of the casting material, there was increased moisture trapping between the skin and the cast, resulting in an increase in SC hydration. Although decreased SC hydration has been reported in dermatoses associated with dry skin, for example asteatotic eczema, ${ }^{13}$ prolonged, excessive skin hydration can conversely lead to increased maceration and break down.

Hypertrichosis refers to excessive hair growth on any part of the body beyond the norm for a patient's age and gender. It has been widely reported following prolonged pressure, for example after cast immobilisation, but is benign and transient. ${ }^{6-9}$ In our study, we did not detect a significant increase in hair density after cast immobilisation. We hypothesise that this may be due to the short casting period ( $\leq 4$ weeks) for our patients.

Overall, the rate of skin complications after casting was found to be $6.7 \%$ in our study, with erythema the most common complication. Itch and malodour associated with casting gradually increased throughout the study period. However, warmth and dampness did not seem to be a concern to most participants. Besides objective measures, subjective symptoms are important to consider when developing new materials for cast immobilisation. If these are too common or excessive, it can lead to adverse outcomes for patients, for example self-removal of casts before fractures are adequately healed or as in one of our cases, insertion of foreign bodies under the cast to relieve itch.

One of the limitations of our study was the relatively small sample size, leading to non-significance of some study parameters. In addition, before the initial set of readings was obtained, all patients had a half cast applied at the Children's Emergency Department or other clinics, albeit only for a few days. This may have underestimated the TEWL level and overestimated stratum corneum hydration value. Lastly, the study questionnaire designed by our investigators had not been validated. However, it was designed to specifically address paediatric patients' perceptions on itch, odour, warmth and dampness caused by casting. The closed-questions were phrased in a way that prevented misunderstandings or ambiguities and only allowed responders to choose one answer from the multiple-choice questions and 5-point rating scales. The flow of the questions was also optimised to enable smooth transition from one question to the next.

In conclusion, the present study suggests that cast immobilisation for up to 4 weeks exerts moderate 
adverse impact on patients' skin, in particular changes in TEWL and SC hydration. Further studies to explore the use of better materials for cast immobilisation to improve skin barrier function and overall patient satisfaction are warranted.

\section{REFERENCES}

1. Cooper C, Dennison EM, Leufkens HGM, Bishop N, van Staa TP. Epidemiology of childhood fractures in Britain: a study using the general practice research database. J Bone Miner Res 2004;19:1976-81.

2. DiFazio R, Vessey J, Zurakowski D, Hresko MT, Matheney $\mathrm{T}$. Incidence of skin complications and associated changes in children treated with hip spica casts for femur fractures. J Pediatr Orthop 2011;31:17-22.

3. DiFazio RL, Harris M, Feldman L, Mahan ST. Reducing the incidence of cast-related skin complications in children treated with cast immobilization. J Pediatr Orthop 2017;37:526-31.

4. DiPaola MJ, Abzug JM, Pizzutillo PD, Herman MJ. Incidence and etiology of unplanned cast changes for fractures in the pediatric population. J Pediatr Orthop 2014;34:643-6.

5. Trueb RM. Causes and management of hypertrichosis. Am J Clin Dermatol 2002;3:617-27.
6. Shannon EG, DiFazio R, Kasser J, Karlin L, Gerbino P. Waterproof casts for immobilization of children's fractures and sprains. J Pediatr Orthop 2005;25:56-9.

7. Ma HJ, Yang Y, Ma HY, Jia CY, Li TH. Acquired localized hypertrichosis induced by internal fixation and plaster cast application. Ann Dermatol 2013;25:365-7.

8. Yuen MW, Lai LKP, Chan PF, Chao DVK. Acquired localised hypertrichosis in a Chinese child after cast immobilisation. Hong Kong Med J 2015;21:369-71.

9. Alsaleem YZ. Hypertrichosis in children after immobilization with plaster of Paris. Ann Coll Med Mosul 2013;39:80-3.

10. Hongbo Z, Maibach HI (Eds). Dermatotoxicology. $6^{\text {th }}$ edition. USA: CRC Press LCC; 2004.

11. Fluhr JW, Dickel H, Kuss O, Weyher I, Diepgen TL, Berardesca E. Impact of anatomical location on barrier recovery, surface $\mathrm{pH}$ and stratum corneum hydration after acute barrier disruption. Br J Dermatol 2002;146:770-6.

12. Goh CL, Khoo L. Laser Doppler Perfusion Imaging (LDPI) and Transepidermal Water Loss (TEWL) values in psoriatic lesions treated with narrow band UVB phototherapy. Dermal vascularity may be useful indicator of psoriatic activity. Ann Acad Med Singapore 2004;33:75-9.

13. Tagami H. Location-related differences in structure and function of the stratum corneum with special emphasis on those of the facial skin. Int J Cosmet Sci 2008;30:413-34. 